\title{
Prison Arts and Future IDs: A Social Art Practice Personal Narrative
}

\author{
Luis Garcia \\ Weingart Center, US \\ Isgarci@icloud.com
}

\begin{abstract}
Prison art programs are essential to helping people with conviction histories develop prosocial behavior, enhancing self-esteem, and strengthening community ties. I know this because participation in prison arts programs helped move me from being a confused young man in prison to what I am today. Despite correctional administrators' robust history of promoting rehabilitation for the incarcerated, statistics on recidivism are daunting with the vast majority of persons released from prison being re-arrested within five years. Traditional rehabilitation programs and legislative efforts to reduce barriers to employment for former inmates are focused on successful community re-entry. However, the quality and diversity of correctional programming beyond job skills training also has implications for community re-entry. Research has linked arts education with development of the right brain functions of focus, creativity, patience, and the ability to work with others. Prison arts programs increase preparation for community re-entry by building skills, positive attitudes toward self and higher learning, and community connections, benefiting returning citizens and contributing to public safety. In California, Arts in Corrections programs, begun in the 1970s but decreased because of funding in 2000, have been re-launched. Led by artist Gregory Sale and highlighted to visitors at Alcatraz, Future IDs is a multiyear, social art project examining individual transformation stories that help reframe the narrative of re-entry. The program allows incarcerated participants to conceive and develop a vision for a future self, reimagining themselves and their positions in society. It also raises public awareness, communicating the value of criminal justice reform, and helping generate the critical community support necessary to reframe the reintegration narrative. Although raised in a supportive environment, the author faced incarceration and the uncertainty that comes with the conflict between official rules and prison culture and with release and recidivism. The Future IDs program's focus on artistic expression helped the author to heal the trauma of dehumanization experienced during incarceration and to regain a sense of self-worth and confidence. Creating his Future ID helped him to find greater clarity about his identity, to liberate himself, and to embrace a new life he walks today in service to others.
\end{abstract}

Keywords: Rehabilitation; recidivism; prison arts programs; public safety; Gregory Sale; Future IDs; Alcatraz; correctional programming; community re-entry; barriers to employment; criminal justice system; social arts programs; reintegration; transformation stories

\section{Introduction}

Throughout the history of correctional institutions, the role of rehabilitation in carceral environments has been shaped by the systemic conflict between security, punishment, and rehabilitation (Silva). Despite this conflict, correctional administrators across the nation have contributed to a robust history of promoting rehabilitation opportunities for the incarcerated. Indeed, as a nineteenth-century State of California correctional administrator said regarding the inherent human potential of access to correctional rehabilitation programs inside the state's nascent correctional system, "Within every man, there is a germ of goodness" (Bookspan xix). However, statistics on recidivism are daunting with the vast majority of persons released from prison being rearrested within five years of release despite concerted efforts at rehabilitation. Statistically, there is no critical mass of successful reintegration into society to highlight when making the case for 
rehabilitation programs, so we must rely on individual success stories to give encouragement and inform new approaches. This essay gives voice to one such story.

My own belief in the transformative potential of correctional rehabilitation programs within the carceral environment originated directly from lived experience as an inmate who accessed correctional rehabilitation opportunities while incarcerated in county and state correctional systems, successfully accomplishing a personal milestone by earning my adult high school diploma while incarcerated in the Los Angeles County jail. These experiences put me on a path to seeking higher education opportunities and to becoming a voice advocating transformation to more inclusive and equitable education environments in custodial settings.

This essay is intended to deepen the understanding of how one type of correctional programming, prison arts, has undergone a renaissance in the California State prison system during a historic era of public safety reform. Both a review of the literature on prison arts initiatives and a personal narrative of one participant in a multi-year social art project titled Future IDs highlight this program with the goals of raising public awareness, changing underlying cultural biases towards the incarcerated, and possibly inspiring some toward individual, positive life change.

\section{Sociopolitical Context}

The United States is well recognized for having the highest prison population rate in the world. The majority of these incarcerated people will inevitably reenter their communities. Reentry ${ }^{1}$ is a pressing national and local policy issue. More than 640,000 individuals were released from state and federal prisons across the country in 2015 (Carson \& Anderson), and another 10.9 million cycle through the nation's jails each year (Minton \& Zheng). Chances of successful reentry are low. Nearly $68 \%$ of people released from state prison in 2005 were rearrested within three years of release, and more than $75 \%$ were rearrested within five years of release (Durose, et al., 2014).

Despite the discouraging national statistics, California's criminal justice system has been reshaped by landmark reforms that began eight years ago. In 2011, the California Legislature passed Assembly Bill 109 (Public Safety Realignment), which shifted responsibility for those with nonviolent, nonsexual, and nonserious convictions from the state prison system to county jail systems in an attempt to reduce prison populations. In 2012, California voters passed Proposition 36, narrowing the Three Strikes law to apply primarily to serious or violent felonies. In 2014, Proposition 47 reduced six minor drug and property offenses from felonies to misdemeanors, prompting the resentencing and release of thousands from county jails and state prisons across the state. Two years later, the passage of Proposition 57 ended the practice of direct file in the juvenile justice system and extended earlier parole opportunities to adults sentenced to prison for nonviolent offenses.

Recognizing the implications of these reforms on reentry issues, the California State Legislature passed historic legislation to reduce barriers to employment for the roughly seven million Californians, or nearly one in three adults, who have an arrest or conviction record that might significantly undermine their efforts to obtain gainful employment. This Ban the Box law (Assembly Bill 1008) was designed to aid people with conviction histories, and to decrease unemployment in communities with concentrated numbers of people impacted by the criminal justice system. However, the quality and diversity of programming beyond job skills training in correctional institutions also has important implications for successful reentry.

\section{Prison Arts Programming}

Charged in part with preparing inmates for reentering their communities, prison administrators are caught between the demands for prison reform and budget restrictions. Although prison arts programs have been targets for budget reductions, research has shown participation in such programs has had powerful effects in increasing preparation for reentry into communities through skills, attitudes and perceptions toward self and higher learning experiences, and connections to the community. In addition, visual, literary and performing arts presentations to the community at large can help to change public perceptions of rehabilitation possibilities and of persons reentering the community after incarceration.

\section{A Review of the Literature}

According to the National Institute of Corrections (2005), correctional administrators have had two primary goals in the administration of correctional systems-the safe operation of the correctional institution, which has been a primary public safety goal, and the provision of correctional programming. Correctional

\footnotetext{
${ }^{1}$ Reentry is defined as "the process of leaving prison and returning to society" (Travis 96).
} 
programming for correctional populations has included employment in correctional industries, mental health and substance abuse treatment, life skills training-such as anger management-and correctional educational programs at all levels from basic education to vocational training and postsecondary education (Klein et al.; Lawrence et al). Historically, correctional programming in the United States has been predicated on the belief that correctional systems could contribute to the rehabilitation of correctional populations (Austin \& Irwin; Lawrence et al.; LoBuglio). Prison arts programs have held a unique place in the institutional setting and have been generally considered ancillary to the traditional correctional programming delivered to the incarcerated.

A review of the literature illuminates how prison arts in the correctional environment can influence human development. Studies have demonstrated that incarcerated participants can benefit in many ways when exposed to the arts programming. Researchers have shown that arts programs could aid participants struggling with issues of self-worth, confidence and empowerment (Matarasso \& Chell; Jermyn). Brewster (2014) found that arts in the prison setting often provided authentic learning experiences that engaged the minds and hearts of the incarcerated. For example, prison arts could lead to improvement in writing skills, greater intellectual agility and creativity, motivation, and enhanced performance in other academic disciplines.

Interdisciplinary research "further suggests a strong linkage between the development of the right brain and prison arts and practice, which in turn, leads to higher-order thinking skills and greater emotional self-regulation" (Brewster 3). Compelling evidence has indicated that a well-developed right brain correlates with focused attention, creativity, intellectual flexibility, patience, self-discipline and the ability to work with others (Brewster; Feder \& Feder; Sautter; Stevens).

Program evaluations of prison arts also have demonstrated that beyond encouraging and facilitating creativity, communication, and reflection, art can teach inmates how to work with a focused discipline (Brewster). Another key benefit of arts programming has been that it can act as a bridge to further learning through building confidence and self-esteem (Brewster \& Merts; Cohen; Silber). Anderson and Overy, Hughes, and Langeild found that the arts have encouraged a state of readiness to learn by increasing selfesteem and developing basic communication and other essential skills. There is also evidence that this is particularly true for those disenfranchised from the formal education system. For example, a majority of participants of prison arts theater programs reengaged with school, including in some cases college courses, while incarcerated (Miles).

An added benefit of many prison arts programs has been the opportunity for inmate-artists to reconnect with the community-at-large through exhibitions of inmates' artwork or performances given by inmates to the public in partnerships that support local nonprofit organizations (Brewster; Schrift). These communitybased activities Brewster (2014) found served to aid incarcerated men and women to demonstrate to themselves and to the public at large that they were more than a prison number and should not be defined solely by the criminal act that brought them to prison.

\section{Public Safety and Prison Arts in California State Prisons}

The primary goal of California's criminal justice system is to provide public safety by deterring and preventing crime, incarcerating people who commit crime, and reintegrating people who became involved the system back into the community. Thus, incarceration carries with it the public responsibility of correctional administrators for the rehabilitation of inmates to aid in their reintegration. ${ }^{2}$

Electrified barbed wire, concrete, and guard towers have formed the physical landscape for California's prison arts programs since the Arts in Corrections (AIC) programs began in California in the late 1970s. Despite this setting, California's AIC programs became world-renowned through the 1980s and early 1990s. In the early 2000s, due to various budgetary and policy decisions, AIC programs dwindled. As a result of the state's budget crisis in 2010, the California Department of Corrections and Rehabilitation (CDCR) closed AIC programs. Ironically, just as the official AIC program was closing, California's state correctional system was undergoing a massive overhaul because of $\mathrm{AB} 109$. Thus, as an emphasis on rehabilitative programs and a reduction of the state's prison population became a public safety priority, AIC supporters had a window of opportunity to advocate for the state to reconsider AIC programs as part of the overall drive to reduce prison populations and increase rehabilitation.

Four years ago, AIC relaunched as a pilot program at $19 \mathrm{CDCR}$ facilities under the auspices of the California Arts Council. In 2017, the program expanded to all 35 CDCR adult institutions. AIC in the CDCR system is an

\footnotetext{
${ }^{2}$ Reintegration is both an event and a long-term process that begins prior to release and continues well afterward in an individual's return (Visher \& Travis).
} 
arts program designed to reduce recidivism by preparing inmates for a successful reintegration into society. The program allows for inmates to express themselves and create self-awareness through the integration of a visual, literary and performing arts curriculum. The program focuses on topics used for strengthening rehabilitation and is facilitated by professional artists and specialized organizations depending on the specific program. In the dehumanizing environment of the prison, inmates can express themselves through drawing, writing, dancing, poetry, acting and other artistic methods. When available, many AIC participants can take advantage of the public exhibitions and performances offered to inmates, giving them the opportunity to showcase their work in partnership with community-based organizations.

\section{Social Art Practice: Future IDs}

Future IDs is a multi-year, social art project examining individual stories of transformation that can collectively help reframe the narrative of reentry. It is led by artist Gregory Sale who co-designed the project with members of the Los Angeles based Anti-Recidivism Coalition (ARC). ARC is a network of community advocates, allies, and members who are committed to justice reform.

Future IDs is comprised of future planning workshops, based on artistic expression, exhibitions and public programs across California. Workshop activities build towards an arts-based public service exhibition on Alcatraz Island. The ID-making workshops are a structured environment for participants to conceive and develop a vision for a future self-for a dream job, a role in society, or a continuing role with family, such as father or mother. The workshops invite participants to question their life trajectory at a deeper level and see how institutional systems intersect with their histories. This is a unique opportunity for participants to envision a future that had been closed off to them, to build their personal stories of transformation that can join other stories to help reframe the narrative of re-entry. Connecting this deeply personal work to visitors at Alcatraz-an immensely popular and iconic American landmark which embodies both romanticized narratives and complex histories of incarceration-is an opportunity to challenge underlying assumptions about incarceration and life after prison among the general public. Viewing a collection of these future IDs artist Gregory Sale commented, "Stimulates the audience to consider its own futures and thereby to identify with the artist-participants. Thus, creating social connections that bring forth the humanity of system-involved individuals" (Personal Interview). The aim of Future IDs is to raise public awareness and change underlying cultural biases of the incarcerated. In this context, the audience feels equal to and connected in some meaningful way to returning citizens.

\section{The Future ID Project: Personal Perspective}

On December 5, 1991, I entered the California Correctional Institution (CCI) State Prison Tehachapi Reception Center as a state prisoner. CCl's setting in the shadow of the picturesque ice-capped peaks of the beautiful Tehachapi mountains stood in stark contrast to the emotions I felt as I entered the dreary, fluorescent amber-lit, grey concrete state prison housing unit. Shuttled in an ordered fashion from the County of Los Angeles Sheriff bus into a metal holding cage with other convicted felons, I waited to be stripped naked and processed into the prison.

As I recall the trauma of that day, I was battling my own very personal adversities, attempting to grasp the magnitude of errant life decisions that had brought me to this critical juncture. I came from a two-parent, middle-class family that cultivated an environment of learning in which I excelled during my middle school years-clearly a support system for success. Yet, during my adolescent high school years in both private and public educational systems, I began a negative trajectory that led first to continuation high school, then to independent studies, and finally to adult school-all without success. Following this trajectory, I eventually slid into numerous incarcerations in the Los Angeles County jail system.

During these periods of incarceration, I attempted to change that trajectory-to follow family models with family support-trying to complete my high school diploma or my General Education Equivalent (GED), but each time to no avail. However, determined to pursue an education after release, I returned home and enrolled in community college and attended classes. I struggled to navigate reentry into family and community while continuing with my studies.

So, here I was on this December day-a young Chicano ${ }^{3}$ male, high school dropout, convicted felon. Pursuing an education was the furthest thing from my mind. I was now California state prisoner H-17161.

\footnotetext{
3 Chicana/o refers to a female or male born in the United States and of Mexican descent. While the term "Chicana/o" started as a derogatory word for referring to Mexicans, it was reclaimed by Mexican-Americans in the 1960's during the student and Chicano movements as a political and unifying responsibility to bring about change for their communities (Acuña). It is also important to
} 


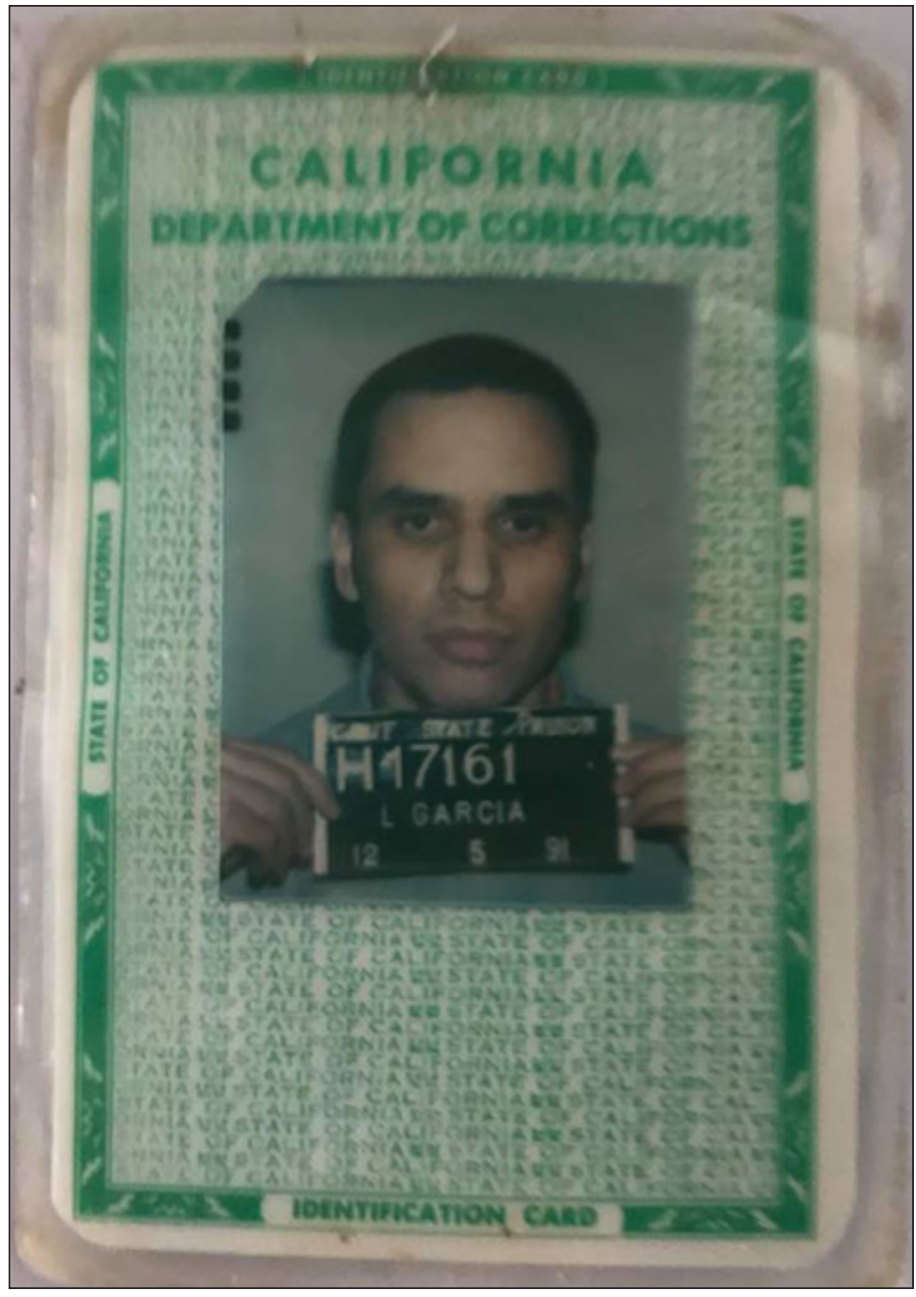

Figure 1: Prison identification card, Luis S. Garcia, 1991. Author's archives.

\section{Opportunities}

All convicted felons who enter state prison undergo required institutional assessments with appropriate rehabilitation program assignments. Shortly after receipt into Tehachapi, I was sent to the education building to take an inmate- proctored Test of Adult Basic Education (TABE). My overall scores were poor. Thus, I was classified to attend adult school-yet another chance to meet success. To my frustration, when I was transferred from the Tehachapi Reception Center to the Tehachapi Level II yard to serve my sentence, I was unable to begin an academic program because of an institutional wait-list.

While waiting for space in the adult school, I secured a prison employment opportunity as an inmate clerk in the institution's vocational inmate programs. I was also able to participate in a creative writing program as part of an AIC program partnership with a local community college-an important step toward educational goals.

These opportunities were interrupted when I was physically assaulted by a gang member, resulting in my removal from the prison yard into the Administrative Segregation Unit. For safety and security purposes I was administratively transferred to another institution. There, I was assigned to various prison employment positions as an inmate clerk as I waited for parole release.

\section{Home Again}

Once again, I returned home and enrolled at my local community college anxious to continue my education. Two years later-and back on the old trajectory-I reoffended. I was once again on my way back to state prison.

During that era, inmate access to educational opportunity remained limited across the jail system. I was very fortunate to have been classified and housed at one of the six jails in the jail system that offered

note that Chicana/o has a philosophical meaning that reclaims indigenous ancestry, the land of Aztlan, and the political, histori$\mathrm{cal}$, and social consciousness of the lived experiences, and the realities of colonization, racism, and internal racism within the U.S. experience (Chicano Coordinating Council 1970). 
education programming while awaiting transfer to state prison once again. There, I had the opportunity to complete my high school education-the foundation to my higher education journey. Despite my own continued personal struggles which resulted in reoffending as a parole violator shortly after this second prison commitment, this was an opportunity that was to be a transformative experience-success.

\section{Dehumanizing Environment of the Prison}

Correctional environments place an extraordinary level of psychological and physical demands on inmates. Criminologists have suggested that the adaptations a prison inmate is likely to develop in the correctional environment are interpersonal distrust, social isolation, and institutional dependence (Haney). In addition, it is likely that, while incarcerated, the inmate becomes the personification of institutionalization. Through this process of institutionalization, the individual becomes accustomed to multiple environmental deprivations-limitations that the correctional environment imposes (Haney). Institutionalized, the inmate is basically dehumanized.

As a young Chicano adult male, I was moved from serving county jail sentences to the hardened environment of the California state prison system. As a matter of survival, I needed to adapt to my surroundings. Emotionally, I had to develop habits of thinking and acting that would be highly dysfunctional and antisocial in civil society. At the very same time, I had to remember who I was as a person, what it was to be human.

Inmate-formulated, lived prison culture is quite different from the formal rules promulgated by prison administration. To survive in the California State prison inmate culture, a Southern Chicano prisoner is required to live by rules of conduct (respect, pride, and heart) in service to the La Raza (the people). While instilling a cultural identity within the group, these rules are also rooted in a twisted allegiance to gang culture in which a Southern Chicano prisoners must view Northern Chicano prisoners as inferior. A Southern Chicano prisoner must align with a mandatory rule: no social interaction with Chicanos from the North or other races. If he does not, he can be assured that harm will come his way. Indeed, a Southern Chicano prisoner will earn respeto-respect-in the prison yard if he assaults another Chicano for breaking a rule. In allegiance to the gang culture, he can earn orgullo-pride-by assaulting another Chicano inmate for

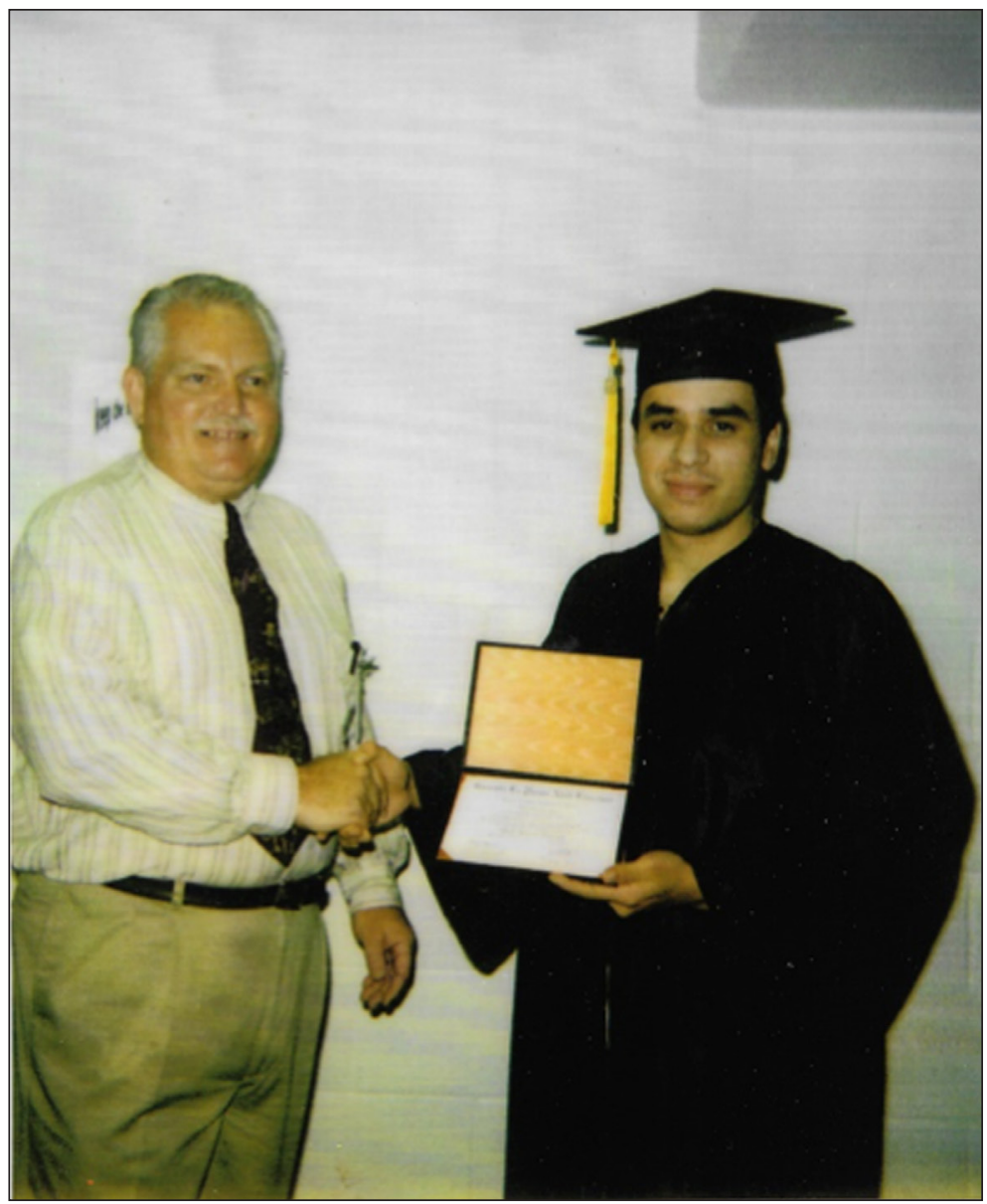

Figure 2: Jail high/school graduation photo, Luis S. Garcia, 1995. Author's archives. 
breaking a rule that disparages the Raza. In this twisted cultural allegiance, if the Chicano inmate commits an assault, he earns recognition as having corazon-heart-for carrying out actions in service to the Raza. Conversely, the Chicano victim who refuses to engage is cast as an outsider to the prison cultura-culture. Ironically, although I was a victim of an inmate assault since I did not snitch on the person by whom I was assaulted, I was never cast out.

In the context of my own numerous jail and prison experiences, I believe the adaptations and adjustments I made were normal reactions to abnormal conditions in the institutional environments. However, these adaptations to institutional environments did not facilitate adapting to normal social environments outside of prison.

When an inmate prepares to exit the correctional environment, adapting to the social environment can be complex. The experiences of institutional patterns of behavior-dependence on the correctional environment-are likely to be a significant barrier that can impact an individual's opportunity for a successful return to society. Although the inmate can readjust and readapt institutional patterns of behavior to more socially appropriate ones suited for civil society, very few inmates exit correctional environments unscathed, and most are completely changed by their experience (Haney; Irwin).

In retrospect, one of the most challenging aspects of my jail and prison experiences has been the process of healing from the trauma of dehumanization experienced during these incarceration experiences.

\section{Social Art Practice: Healing the Trauma}

"For the things we have to learn before we can do them, we learn by doing them."

-Aristotle, Nicomachean Ethics

Artistic expression is one of the best defenses an inmate or a person returning home can have to cope with prison's dehumanization. In the prison environment, the prisoner is stripped of everything that matters in his life-except time. Navigating the daily institutional routines to survive-how to survive-is key to his survival. The daily institutional routine is less depressing if he engages in an activity that will make time pass more interestingly and quickly. For some it may playing dominoes, cards, chess, sports activities or artistic expression. The ability to cultivate the imagination by artistic expression not only allows the prisoner to mentally escape from his environment, it provides spiritual nourishment in the deep recesses of the soul-an outlet for the expression of hidden emotions from others-to survive the volatile and hostile environment.

As a participant in the Future IDs project, I have encountered men and women from all races and ethnic backgrounds who have experienced incarceration and were determined to reinvent themselves in mainstream society. In conversations with workshops participants, I have shared that my own path has been guided by reclaiming my own sense of personal self-worth and confidence, and that despite my experiences of incarceration, my life is worth infinitely more. In the process of developing my Future ID, I was taken back to an early memory of my youth when as a young child my parents took me to the Chicano Moratorium march on August 29, 1970. Held in East Los Angeles, the moratorium was the largest anti-Vietnam War demonstration by any minority group in the United States. Estimates of the demonstrators, mostly Chicanos, range from 20,000 to 30,000. The Chicano Movement of the late 1960s and 1970s was the most significant civil rights and community empowerment movement by Mexican Americans in U.S. history. It was in this memory that I recognized my Chicano identity was not marred by my prison past. On the contrary, I recognized my Chicano identity was rooted in resilience and centuries of survival since the Spanish conquest.

As a young child, my father always made it a point that I knew about my Chicano culture, often to the disdain of my mother who cared more about raising a family. I vividly remember as a kid, my father sharing his adamant beliefs that Aztlan would return. Our people from Tlaxcala, my father would share, were an advanced civilization that spread from Mexico to the Southwest. He felt that one day we would have our land returned. Although young and respectful of my father, internally I always challenged his beliefs. For many years as an adolescent and well into adulthood, I defiantly opposed my father's belief. After surviving my jail and prison experiences and completing my higher education journey, in one of the Future ID workshops, I was able to reflect on how I had created an internal wall around my identity for self-protection. It was then the earlier messages of understanding my culture made sense. Specifically, my father's wisdom was rooted in a spiritual worldview rather than literal. Thus, in the process of creating my Future ID, I found it possible to reach a greater clarity about who I am today, to liberate myself, and recognize my transformation from the past dehumanizing experiences into a deepened self-awareness of embracing this new life I walk in service to others. 


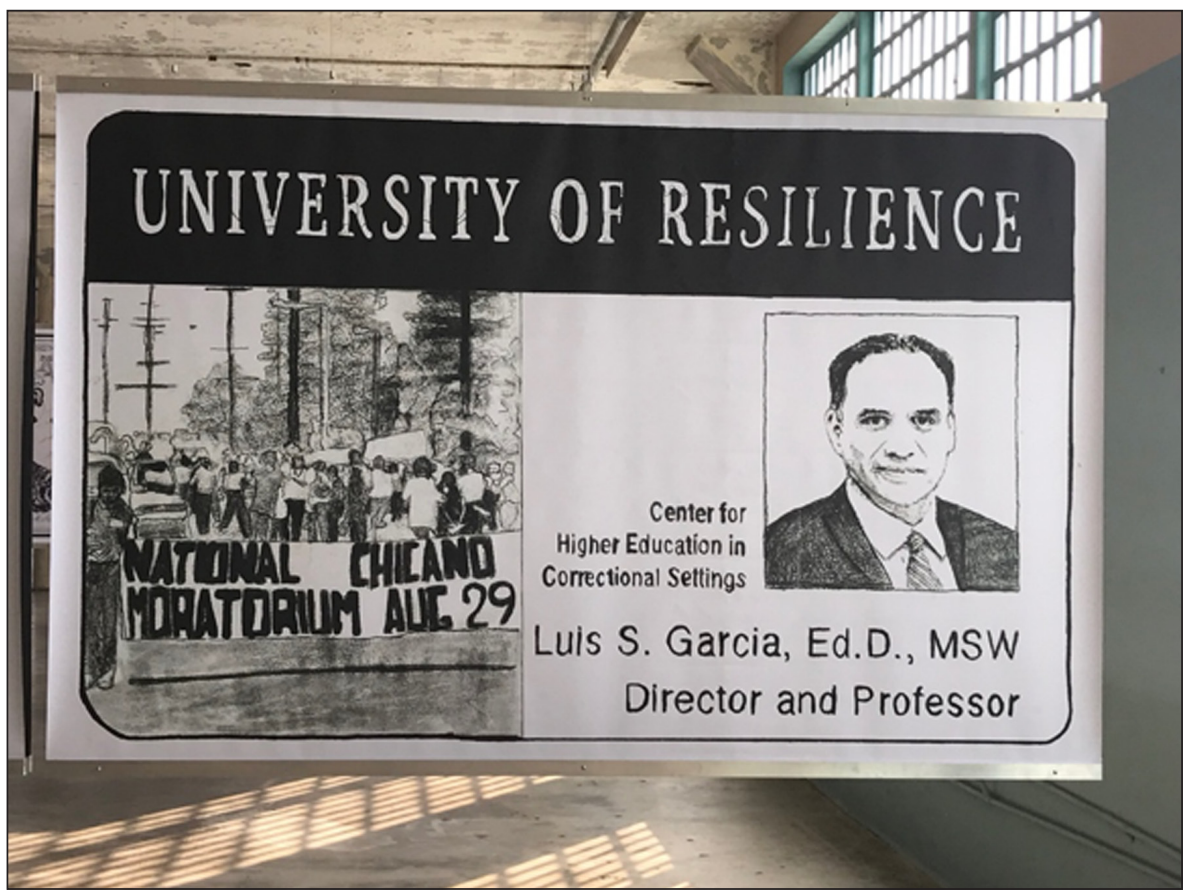

Figure 3: Future ID, Dr. Luis S. Garcia, 2017. Author's archives.

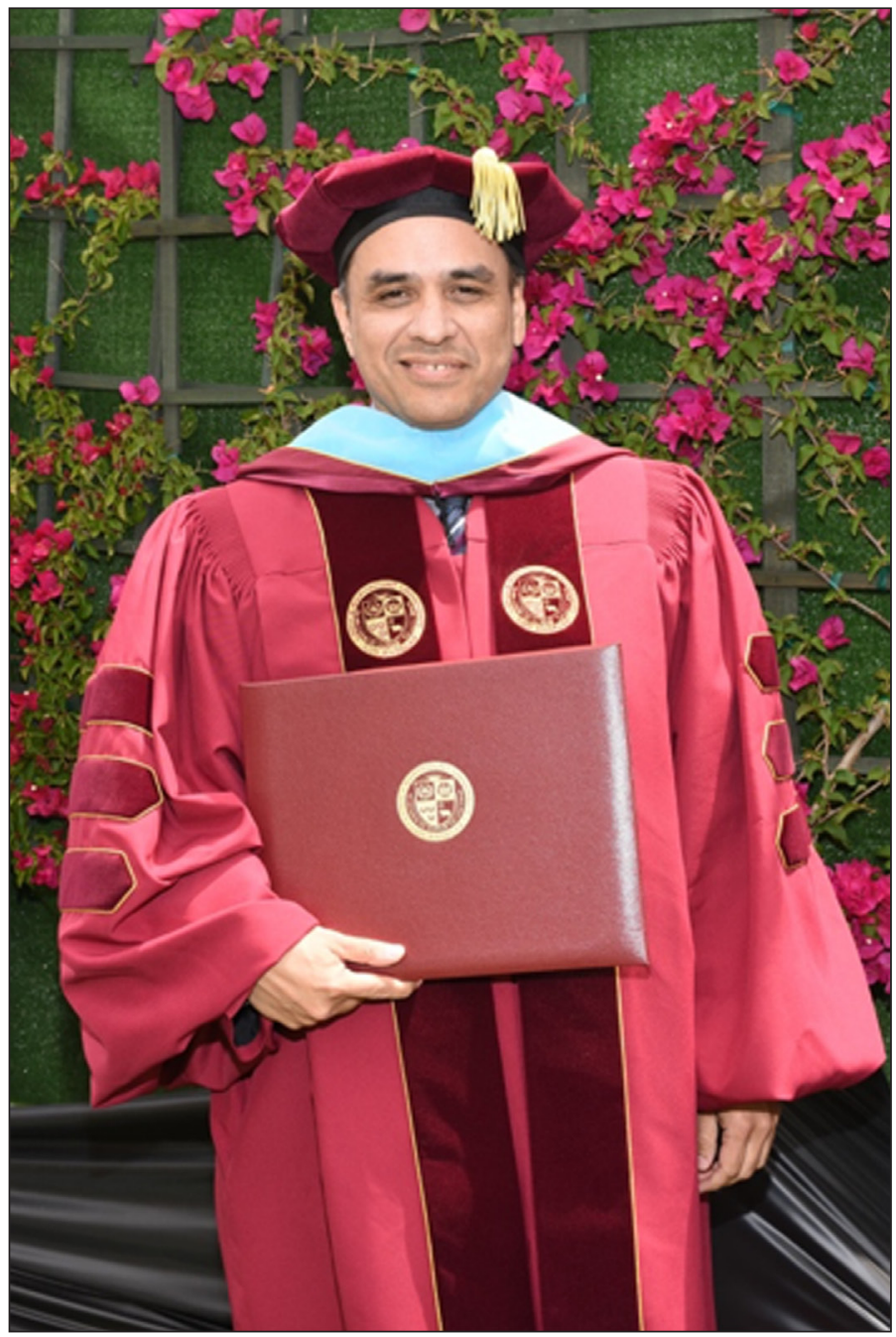

Figure 4: Luis S. Garcia, Ed.D., MSW, 2017. 


\section{Concluding Thoughts}

Prison art programs are essential to helping people with conviction histories develop prosocial behavior, enhancing self-esteem, and strengthening community ties. I know this because participation in a prison arts programs helped move me from being a confused young man in prison to what I am today.

With the renaissance of this type of correctional programming during a historical period in public safety reform in the State of California, correctional administrators have embraced a viable public safety contribution by offering inmates increased access to the arts that can benefit returning citizens. The Future IDs program's embrace of the incarcerated and of persons at risk of recidivism allows them to reconsider the complexity of reintegration. It encourages them to take the role of using their personal creative expression to reimagine themselves and their positions in society. It has the added benefit of communicating the value of criminal justice reform to the general public and thereby can help to generate the critical community support necessary to help reframe the narrative of reintegration.

\section{Competing Interests}

The author has no competing interests to declare.

\section{References}

Acuna, R. Occupied America: The History of Chicanos, 5th ed. Pearson Longman, 2004.

Anderson, K., and Katie Overy. "Engaging Scottish Young Offenders in Education Through Music and Art." International Journal of Community Music, vol. 3, no. 1, 2010, pp. 47-64. DOI: https://doi.org/10.1386/ ijcm.3.1.47/1

Aristotle. The Nicomachean Ethics. Translated by J.A.K. Thompson, Penguin, 2004.

Austin, J., and J. Irwin. It's About Time: America's Imprisonment Binge. Wadsworth, 2001.

Bookspan, S. A Germ of Goodness: The California State Prison System, 1851-1944 (Vol. 3). University of Nebraska Press, 1991.

Brewster, L. "An Evaluation of the Arts-in-Corrections Program of the California Department of Corrections", 1983, williamjamesassociation.org/prison_arts/. Accessed 15 October 2017.

Brewster, L. California Prison Arts: A Quantitative Evaluation. Santa Cruz, CA: William James Association, 2014, williamjamesassociation.org/california-prison-arts-evaluation-2014. Accessed 15 October 2017.

Brewster, L., and P. Merts. Paths of Discovery: Art Practice and Its Impact in California Prisons, 2012, www. createspace.com/3916681. Accessed 15 October 2017.

Carson, E., and E. Anderson. Prisoners in 2015. Washington, DC: Bureau of Justice Statistics, 2016.

Chicano Coordinating Council. (1970) El Plan de Santa Barbara. Santa Barbara, CA: La Causa.

Cohen, M. L. "Choral Singing and Prison Inmates: Influences of Performing in a Prison Choir." The Journal of Correctional Education, vol. 60, no. 1, 2009, pp. 52-65.

Durose, M. R., A. D. Cooper, and H. N. Snyder. Recidivism of Prisoners Released in 30 States in 2005: Patterns from 2005 to 2010. Washington, DC, Bureau of Justice Statistics, 2014.

Feder, E., and B. Feder. The Expressive Art Therapies. Prentice-Hall Inc, 1981. DOI: https://doi. org/10.2307/1444056

Hughes, J. Doing the Arts Justice-A Review of Research Literature, Practice and Theory. Berkeley, CA: The Unit for the Arts and Offenders Centre for Applied Theatre Research, 2005, artscouncil.org.uk/publication_ archive/doing-thearts-justice-a-review-of-research-literature-practice-and-theory/. Accessed 15 October 2017.

Jermyn, H. The Arts and Social Exclusion: A Review Prepared for the Arts Council of England, 2001, artscouncil. org.uk. Accessed 15 October 2017.

Klein, S., M. Tolbert, R. Burgarin, E. F. Cataldi, and G. Tauschek. Correctional Education: Assessing the Status of Prison Programs and Information Needs. MPR Associates, 2004, mpinc.com/. Accessed 15 October 2017.

Lawrence, S., D. P. Mears, G. Dubin, and J. Travis. The Practice and Promise of Prison Programming. The Urban Institute, 2002.

LoBuglio, S. "Time to Reframe Politics and Practices in Correctional Education." Annual Review of Adult Learning and Literacy. Edited by J. Comings, B. Garner, \& C. Smith. Vol. 2, pp. 111-150. National Center for the Study of Adult Learning and Literacy, 2001.

Matarasso, F., and J. Chell. Vital Signs: Mapping Community Art in Belfast. Comedia, 1998.

Miles, A. "Give Prison Arts Projects a Break." The Guardian, 8 March 2007, theguardian.com/artanddesign/ artblog/2007/mar/08/giveprisonartsprojectsabr. Accessed 15 October 2017.

Minton, T., and Z. Zheng. Jail Inmates in 2015. Washington, DC: Bureau of Justice Statistics, 2016. 
National Institute of Corrections. Evidence-based practice: Principles for Enhancing Correctional Results in Corrections. Washington, DC, 2005.

Sale, G. "Personal Interview." 24 June 2018. DOI: https://doi.org/10.4171/NEWS/110/8

Sautter, R. C. An Arts Education School Reform Strategy. Phi Delta Kappan, vol. 75, no. 6, 1994, pp. 432-437.

Schrift, M. "Angola Prison Art: Captivity, Creativity, and Consumerism." Journal of American Folklore, vol. 119, no. 473, 2006, pp. 257-275. DOI: https://doi.org/10.1353/jaf.2006.0035

Silber, L. "Bars Behind Bars: The Impact of a Women's Prison Choir on Social Harmony." Music Education Research, vol. 7, no. 2, 2005, pp. 251-271. DOI: https://doi.org/10.1080/14613800500169811

Silva, W. "A Brief History of Prison Higher Education in the United States." Higher Education in Prison. Edited by M. Williford. American Council on Education and Oryx Press, 1994, pp. 17-31.

Stevens, V. The Importance of Creativity, Emotional Intelligence and the Arts for Education in the 21st Century. Presented at the National Academy of Recording Arts and Sciences, 2000, drvictoriastevens.com/PDFs/V. Stevens_ArtEd_Handouts_SF_7-10.pdf. Accessed 15 October 2017.

Travis, J. But They All Come Back: Facing the Challenges of Prisoner Reentry. The Urban Institute, 2005.

Visher, C. A. \& J. Travis. "Transitions from Prison to Community: Understanding Individual Pathways." Annual Review of Sociology, vol. 29, 2003, pp. 89-113. DOI: https://doi.org/10.1146/annurev. soc.29.010202.095931

How to cite this article: Garcia, L 2019 Prison Arts and Future IDs: A Social Art Practice Personal Narrative. Anthurium, 15(2): 3, 1-10. DOI: https://doi.org/10.33596/anth.386

Published: 23 September 2019

Copyright: (c) 2019 The Author(s). This is an open-access article distributed under the terms of the Creative Commons Attribution 4.0 International License (CC-BY 4.0), which permits unrestricted use, distribution, and reproduction in any medium, provided the original author and source are credited. See http://creativecommons.org/licenses/by/4.0/. 